\title{
Rancang Bangun Audio Video Vmix Console pada Pertunjukan Live Stream Youtube
}

\author{
Citra Devi Murdaningtyas ${ }^{1}$, Novita Astin ${ }^{2}$, Dwi Susanto ${ }^{3 *}$ \\ ${ }^{1,2,3}$ Politeknik Elektronika Negeri Surabaya \\ *dwi@pens.ac.id
}

\begin{abstract}
Performing the Audio Video mixing process requires a tool in the form of a mixer, but the price of a mixer on the market is still very expensive. One of the software that can be used to become a video mixer is the VMix software. VMix software is a video mixer and switcher software that takes advantage of the latest advances in computer hardware to provide live HD video mixing. However, the VMix software is a virtual mixer that runs using a keyboard and mouse so there are limitations in running the software. We need an alternative tool that can be used when running the VMix software. By using the Arduino Uno CH340 device as a microcontroller, Hairless MIDI as a link between Arduino and Windows to send and receive MIDI signals, LoopMIDI as a virtual MIDI device that connects Hairless MIDI and VMix, can make a console-shaped device that can be used when running the VMix software. Therefore, in a study entitled "Design and Build Audio Video Vmix Console on Youtube Live Stream Show", it is hoped that it can produce a tool that can be used during live broadcasts using the VMix software on Live Stream on Youtube. From the results of testing the VMix for Video Console on the VMix software when live streaming on Youtube, the video was successfully controlled using this console with a success rate of 95\%, while the ergonomic was successful.
\end{abstract}

Keywords : console, mixer, live broadcast, vMix software.

\begin{abstract}
Abstrak
Melakukan proses mixing Audio Video diperlukan sebuah alat yang berupa mixer, namun harga mixer di pasaran masih sangatlah mahal. Salah satu software yang dapat digunakan untuk menjadi video mixer adalah software VMix. Software VMix yaitu software mixer dan switcher video yang memanfaatkan kemajuan terbaru di dalam perangkat keras komputer untuk menyediakan video mixing HD secara langsung. Namun dikarenakan software VMix merupakan mixer virtual yang dijalankan dengan menggunakan keyboard dan mouse, maka terdapat keterbatasan dalam menjalankan software tersebut. Maka diperlukan suatu alat alternatif yang dapat digunakan pada saat menjalankan software VMix. Dengan menggunakan perangkat Arduino Uno CH340 sebagai mikrokontroler, Hairless MIDI sebagai penghubung Arduino dengan Windows untuk mengirim dan menerima sinyal MIDI, LoopMIDI sebagai virtual MIDI device yang menjadi penghubung antara Hairless MIDI dan VMix, dapat membuat sebuah alat berbentuk console yang dapat digunakan saat menjalankan software VMix. Penelitian ini diharapkan dapat menghasilkan sebuah alat yang dapat digunakan saat siaran langsung menggunakan software VMix pada Live Stream di Youtube. Dari hasil pengujian Console VMix for Video pada software VMix ketika live streaming di Youtube video berhasil dikontrol dengan menggunakan console dengan tingakat keberhasilan 95\%, sedangkan untuk tingkat ergonomisnya yang baik.
\end{abstract}

Kata kunci : console, mixer, siaran langsung, software vMix. 


\section{Pendahuluan}

Di era digital ini, internet sudah menjadi salah satu media yang dapat memenuhi kebutuhan manusia. Kebutuhan primer seperti sandang, pangan, dan papan juga dengan mudahnya dicari dan didapatkan di internet. Tidak hanya itu, kebutuhan sekunder seperti hiburan juga dengan mudahnya diakses melalui situs-situs tertentu seperti YouTube. Selain menjadi penonton, hampir semua orang juga dapat berkontribusi untuk membuat video yang dapat menghibur orang lain. Jika video yang memerlukan editing dapat memakan waktu yang cukup lama untuk dibuat, maka kreator dapat melakukan live stream dan mereka tidak perlu melakukan proses editing.

Live stream sendiri dapat dilakukan melalui handphone ataupun komputer[1], dan salah satu konten live stream yang dapat menarik minat penonton adalah live stream game. Jika live stream dilakukan dengan komputer, maka ada beberapa hal teknis yang perlu diperhatikan seperti performa yang didapat dengan spesifikasi komputer yang digunakan, spesifikasi minimal dari game tersebut, serta penggunaan daya dari hardware ketika sedang live stream disaat menjalankan game.

Di luar sana, ada banyak software yang dapat digunakan untuk live stream dan salah satunya adalah VMix. VMix adalah software yang memiliki banyak fitur dan dapat digunakan untuk memproduksi film dan video. Beberapa contoh dari fitur-fitur tersebut adalah pengguna diberi kebebasan untuk menambahkan jumlah kamera, video, gambar, audio, teks, powerpoint, perangkat virtual, chroma key, dan masih banyak lagi. VMix sendiri juga mendukung penggunaan kamera yang berjumlah satu ataupun lebih[2].

\section{Metoda Penelitian}

Pada bagian ini, akan dijelaskan tentang rancangan metodologi yang digunakan untuk pelaksanaan penelitian ini dengan blok diagram. Blok diagram metodologi pembuatan
Audio Video Vmix Console dapat dilihat pada Gambar 1.

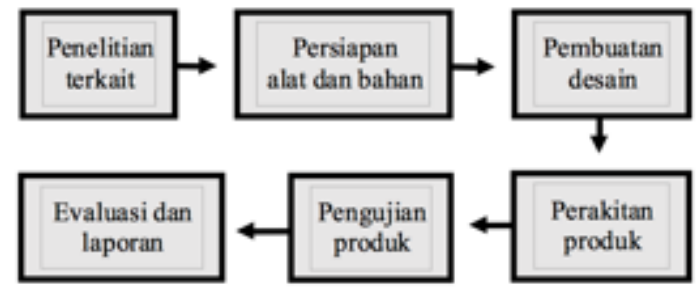

Gambar 1. Blok diagram metodologi pembuatan Audio Video Vmix Console

Dalam melaksanakan penelitian ini akan dilakukan metode kualitatif yaitu pengamatan mendalam berupa pemberian beberapa pertanyaan kepada user dan juga akan dilakukan perhitungan terhadap hasil yang diperoleh.

\subsection{Alat dan Bahan}

Pembuatan Console VMix for Audio membutuhkan beberapa macam hardware dan software tertentu agar dapat berjalan dengan baik. Hardware dan software tersebut adalah:

1. Hardware:

- Laptop

- Arduino Uno

- Printed Circuit Board

- Potentiometer

- Jumper Cables

- Acrylic

2. Software:

- Arduino IDE

- Xloader

- LoopMIDI

- Hairless MIDI to Serial Bridge

- Vmix

\subsection{Pembuatan Desain}

Setelah alat dan bahan sudah disiapkan, maka proses dilanjutkan dengan mendesain produk. Desain yang dibuat adalah desain dari hasil akhir dari Audio Video Vmix Console. Hal-hal penting yang perlu diperhatikan selain alat yang dipilih dan bahan yang digunakan adalah ukuran dan bentuk dari produk yang akan dibuat. Bahan dasar yang digunakan untuk 
membuat case dari Audio Video Vmix Console ini adalah akrilik. Case akan dibuat dengan bentuk balok yang diatasnya terdapat lubang untuk tombol dan potensiometer yang terpasang pada PCB agar dapat dioperasikan. Untuk lebih jelasnya, desain case Audio Video Vmix Console jika dilihat dari atas dapat dilihat pada Gambar 2.

Gambar 2. Desain case Audio Video Vmix Console

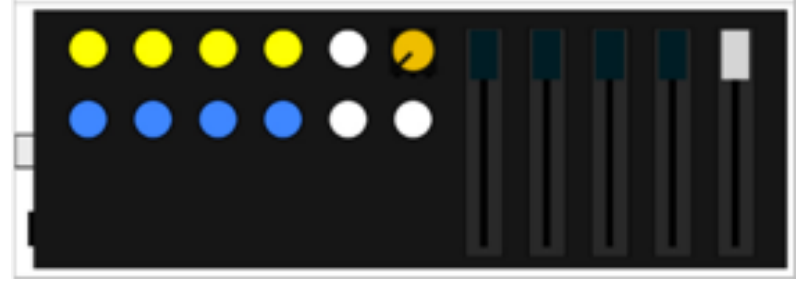

Pada bagian atas case Console VMix beberapa push button dan potensiometer yang memiliki fungsinya masing-masing. Push button yang berwarna kuning berfungsi sebagai preview button, push button biru berfungsi sebagai active button, push button putih sebagai transition button, potensiometer kuning sebagai master volume, 4 buah potensiometer geser

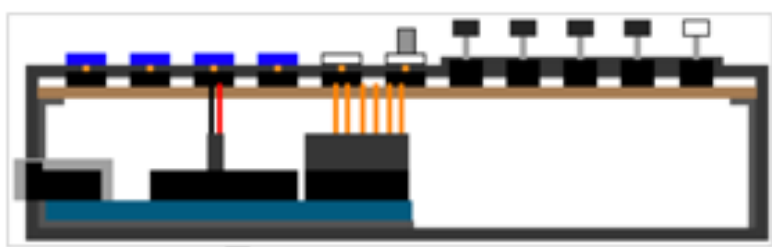

hitam berfungsi sebagai volume fader dari masing-masing channel, dan sebuah potensiometer geser putih sebagai switcher. Pada bagian dalam Audio Video Vmix Console terdapat susunan dari Arduino Uno, kabel jumper, dan PCB. Desain bagian dalam dari Console VMix dapat dilihat pada Gambar 3.

Gambar 3. Desain bagian dalam dari Audio Video Vmix Console

\subsection{Perakitan Produk}

Dengan adanya desain produk, maka proses perakitan produk akan menjadi lebih mudah.Untuk lebih jelasnya, alur perakitan Audio Video Vmix Console dapat dilihat pada Gambar 4.

Tahap awal dari pembuatan produk ini adalah memasang semua tombol dan potensiometer yang sudah disiapkan ke breadboard. Setelah semua tombol dan potensiometer telah terpasang, hubungkan masing-masing tombol dan potensiometer dengan Arduino Uno menggunakan kabel jumper.

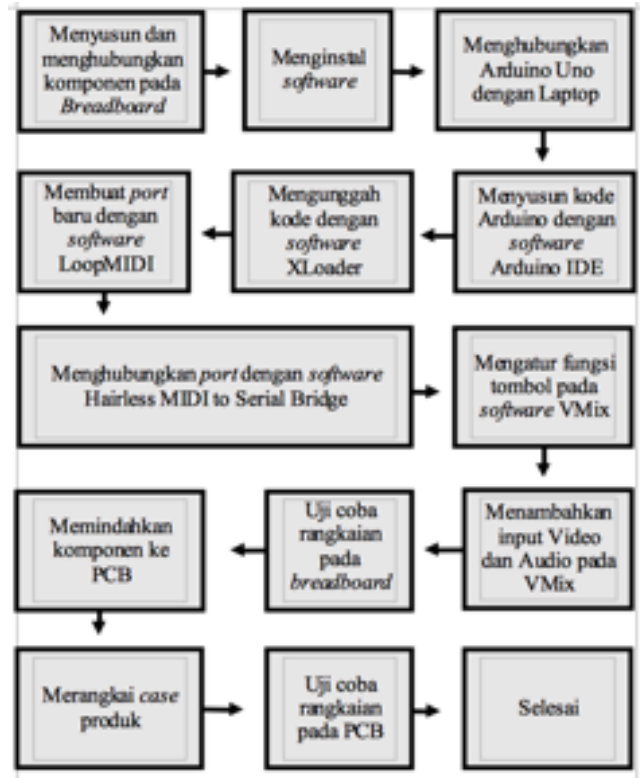

Gambar 4. Blok diagram alur perakitan Audio Video Vmix Console

Jika sudah selesai, maka dilanjutkan dengan menginstal beberapa software yang dibutuhkan seperti Arduino IDE, XLoader, LoopMIDI, Hairless MIDI to Serial Bridge, dan Vmix. Masing-masing software yang telah diinstall juga perlu diatur lagi agar tiap tombol yang terpasang dapat dikenali oleh Arduino Uno maupun sistem operasi yang digunakan. Sambungkan rangkaian Arduino Uno ke port USB pada laptop. Buka software LoopMIDI untuk membuat port baru. Jika sudah, maka buka software Hairless MIDI to Serial Bridge untuk menghubungkan port yang telah dibuat tadi dengan port pada laptop. Untuk mengatur fungsi dari tiap tombol, maka terdapat menu shortcut pada software VMix. Menu ini bekerja dengan cara merekam tombol yang ditekan pada saat itu juga dan kemudian pengguna dapat memberi suatu perintah yang ada. 


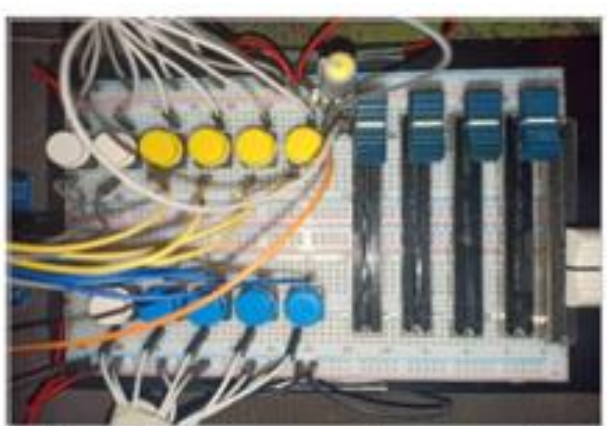

Gambar 5. Potensiometer geser dan tombol yang sudah terpasang pada breadboard

\section{Hasil Penelitian}

Pada bagian ini menjelaskan mengenai hasil uji coba Audio Video Vmix Console dan analisa untuk mengetahui apakah console yang telah dibuat dapat berfungsi dengan baik. Hasil uji coba dilakukan dengan mengoperasikan console yang dihubungkan dengan software Vmix. Hasil dari Audio Video Vmix Console dapat dilihat pada Gambar 6.

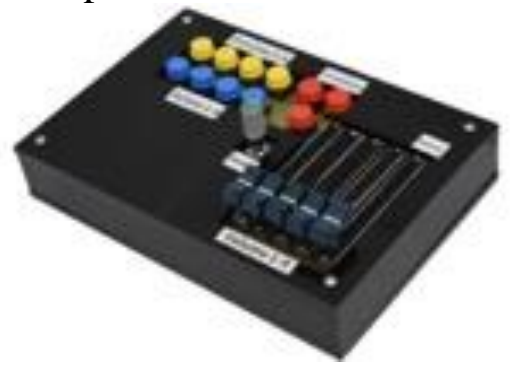

Gambar 6. Audio Video Vmix Console

Audio Video Vmix Console mempunyai dimensi dengan panjang $19.1 \mathrm{~cm}$, lebar $14.3 \mathrm{~cm}$ dan tinggi $9.5 \mathrm{~cm}$. Dengan dimensi yang kecil maka penggunaan console ini lebih dinamis.

\subsection{Pengujian Live Stream Youtube}

Pengujian ini merupakan pengujian untuk Audio Video Vmix Console apakah console dapat digunakan dengan baik pada software VMix dan dapat berfungsi ketika melakukan live streaming di Youtube. Untuk pengujian ini akan menggunakan input berupa video. Terdapat 4 video sebagai input untuk menyesuaikan dengan banyak tombol preview dan tombol active. Untuk lebih jelasnya, tampilan video input dapat dilihat pada Gambar 7.
Dalam pengujian pertama, akan dilakukan pengujian untuk tombol preview. Tombol preview berfungsi untuk mengganti tampilan preview pada software VMix. Tampilan preview tidak akan muncul pada tampilan live streaming di Youtube.

Jika tombol preview ditekan, maka tampilan preview akan terganti dengan video input sesuai dengan channel tombol preview yang ditekan. Untuk lebih jelasnya, perubahan tampilan preview saat tombol preview ditekan dapat dilihat pada Gambar 8.

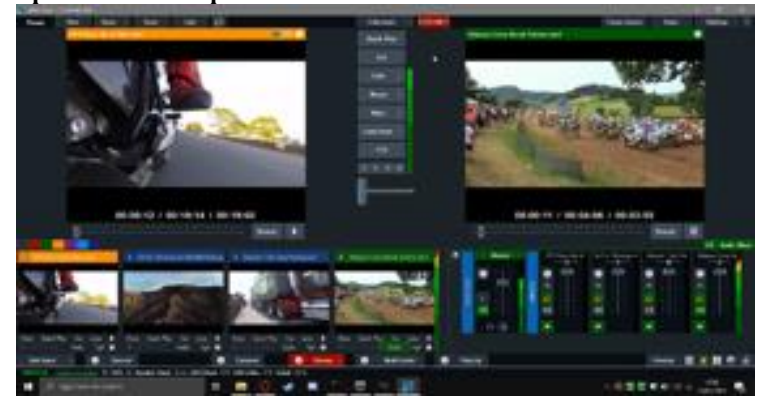

Gambar 7. Tampilan Video Input

Dapat dilihat dari Gambar 7 dan Gambar 8 memiliki tampilan preview yang berubah, hal tersebut menandakan bahwa pengujian untuk tombol preview pada software VMix berhasil. Untuk pengujian selanjutnya adalah pengujian tombol active pada software Vmix. Tombol active berfungsi untuk mengganti tampilan active pada software VMix. Tampilan active adalah tampilan yang ditampilkan pada saat melakukan live streaming di Youtube.

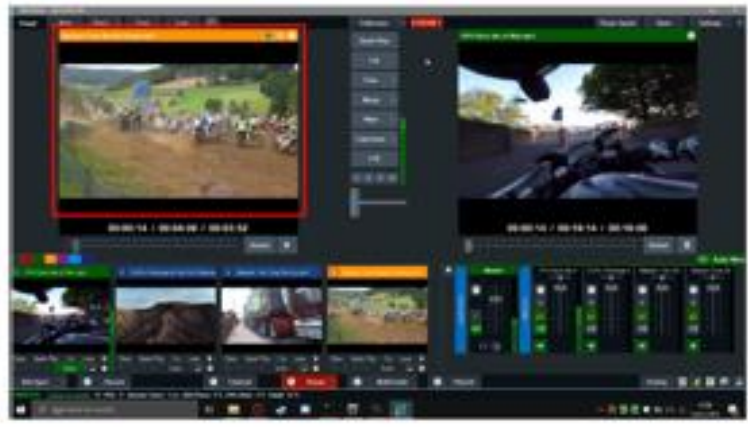

Gambar 8. Perubahan tampilan preview saat tombol preview ditekan

Jika tombol active ditekan, maka tampilan active akan berubah sesuai dengan video input sesuai dengan channel tombol active yang ditekan. Hal tersebut menandakan pengujian 
dari tombol active pada software VMix berhasil. Untuk lebih jelasnya, perubahan tampilan active saat tombol active ditekan dapat dilihat pada Gambar 9.

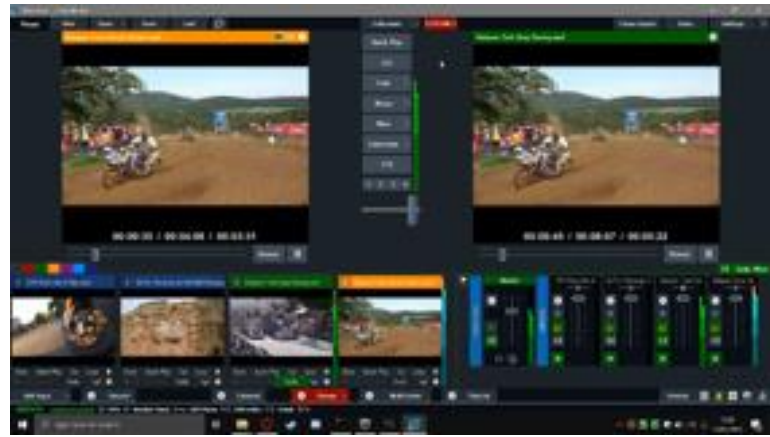

Gambar 9. Perubahan tampilan active saat tombol active ditekan

Untuk tampilan live streaming di Youtube dapat dilihat pada Gambar 10.

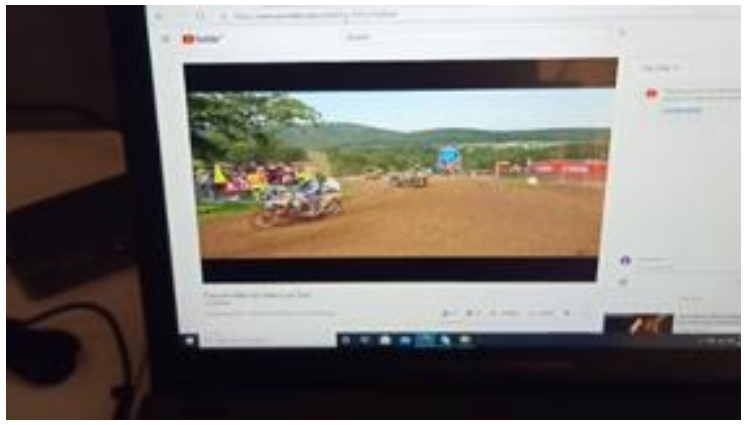

Gambar 10. Tampilan live streaming di Youtube

Pengujian selanjutnya yaitu pengujian untuk tombol transition pada software VMix. Tombol transition berfungsi sebagai tombol untuk mengganti tampilan active yang diambil dari video input pada tampilan preview dengan efek transisi tertentu yang telah diatur saat mapping shortcut. Untuk lebih jelasnya, tampilan pada saat tombol transition ditekan dapat dilihat pada Gambar 11.

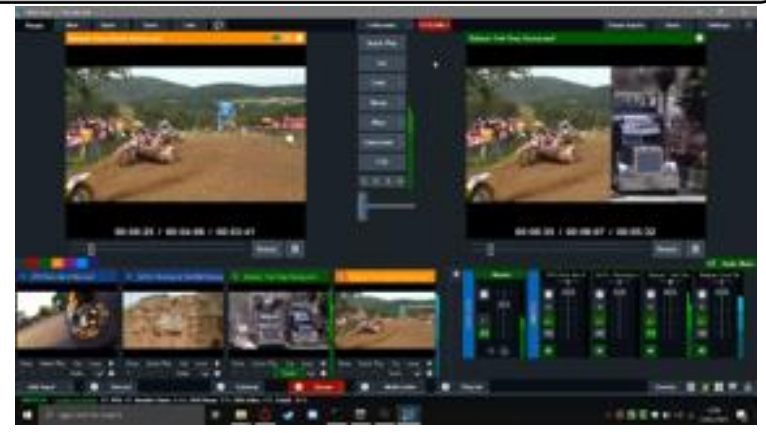

Gambar 11. Tampilan saat tombol transition ditekan

Dapat dilihat pada Gambar 11, tampilan active terdapat transisi dengan efek wipe yaitu tampilan dari preview yang akan menggantikan tampilan active seakan-akan menyapu tampilan active. Dengan begitu pengujian tombol transition pada software VMix berhasil.

Pengujian berikutnya merupakan pengujian potensiometer geser yang berfungsi sebagai switcher pada software VMix. Ketika potensiometer digeser, maka tampilan preview akan menggantikan tampilan active. Perbedaan dari potensiometer sebagai switcher dengan tombol transition adalah switcher menggunakan efek transisi "set fader" yaitu dimana pada saat potensiometer digeser maka video input pada tampilan active akan menghilang dan digantikan dengan video input dari tampilan preview. Pergantian video input pada tampilan active dapat dilakukan secara perlahan maupun cepat sesuai dengan kecepatan menggeser potensiometer. Untuk lebih jelasnya, perubahan tampilan active saat potensiometer digeser dapat dilihat pada Gambar 12.

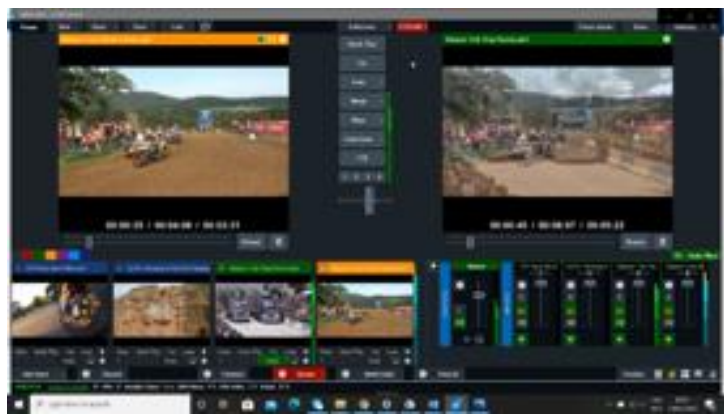

Gambar 12. Perubahan tampilan active saat potensiometer digeser 
Terlihat pada Gambar 12, pada saat potensiometer digeser video input padatampilan active akan digantikan dengan video input dari tampilan preview. Tampilan active menghilang perlahan sesuai dengan posisi switcher. Bukti bahwa switcher dapat digerakkan dapat dilihat pada anak panah berwarna merah. Di situ terlihat switcher berada pada posisi tengah dan video input dari tampilan active belum sepenuhnya menghilang dan tergantikan. Dari hasil pengujian di atas dapat disimpulkan pengujian Console VMix for Video pada software VMix ketika live streaming di Youtube berhasil. Untuk lebih jelasnya, pengujian Console VMix for Video pada Software VMix ketika live streaming di Youtube dapat dilihat pada Tabel 1.

Tabel 1.Tabel pengujian alat ketika live streaming di Youtube

\begin{tabular}{|c|c|c|c|c|}
\hline Yang diuji & Indikator & Harapan & Hasil & Status \\
\hline $\begin{array}{l}\text { Tombol } \\
\text { Preview }\end{array}$ & $\begin{array}{l}\text { Tampilan } \\
\text { preview dapat } \\
\text { berubah } \\
\text { sesuai } \\
\text { channel yang } \\
\text { dipilih }\end{array}$ & $\begin{array}{l}\text { Video } \\
\text { input } \\
\text { pada } \\
\text { tampilan } \\
\text { preview } \\
\text { dapat } \\
\text { berubah }\end{array}$ & $\begin{array}{l}\text { Tampilan } \\
\text { preview dapat } \\
\text { berubah } \\
\text { sesuai } \\
\text { channel yang } \\
\text { dipilih }\end{array}$ & Berhasil \\
\hline $\begin{array}{l}\text { Tombol } \\
\text { Active }\end{array}$ & $\begin{array}{l}\text { Tampilan } \\
\text { active dapat } \\
\text { berubah } \\
\text { sesuai } \\
\text { channel yang } \\
\text { dipilih }\end{array}$ & $\begin{array}{l}\text { Video } \\
\text { input } \\
\text { pada } \\
\text { tampilan } \\
\text { active } \\
\text { dapat } \\
\text { berubah }\end{array}$ & $\begin{array}{l}\text { Tampilan } \\
\text { active dapat } \\
\text { berubah } \\
\text { sesuai } \\
\text { channel yang } \\
\text { dipilih }\end{array}$ & Berhasil \\
\hline $\begin{array}{l}\text { Tombol } \\
\text { Transition }\end{array}$ & $\begin{array}{l}\text { Tampilan } \\
\text { active dapat } \\
\text { berubah } \\
\text { dengan video } \\
\text { input dari } \\
\text { tampilan } \\
\text { preview }\end{array}$ & $\begin{array}{l}\text { Video } \\
\text { input } \\
\text { pada } \\
\text { tampilan } \\
\text { active } \\
\text { dapat } \\
\text { berganti } \\
\text { dengan } \\
\text { video } \\
\text { input } \\
\text { pada } \\
\text { tampilan } \\
\text { preview }\end{array}$ & $\begin{array}{l}\text { Tampilan } \\
\text { active dapat } \\
\text { berubah } \\
\text { dengan video } \\
\text { input dari } \\
\text { tampilan } \\
\text { preview }\end{array}$ & Berhasil \\
\hline $\begin{array}{l}\text { Potensiometer } \\
\text { Geser } \\
\text { Sebagai } \\
\text { Switcher }\end{array}$ & $\begin{array}{l}\text { Switcher pada } \\
\text { software } \\
\text { VMix dapat } \\
\text { digerakkan } \\
\text { dan tampilan } \\
\text { active } \\
\text { berubah } \\
\text { dengan video } \\
\text { input dari } \\
\text { tampilan }\end{array}$ & $\begin{array}{l}\text { Video } \\
\text { input } \\
\text { pada } \\
\text { tampilan } \\
\text { active } \\
\text { dapat } \\
\text { berubah } \\
\text { dengan } \\
\text { video } \\
\text { input } \\
\end{array}$ & $\begin{array}{l}\text { Switcher pada } \\
\text { software } \\
\text { VMix dapat } \\
\text { digerakkan } \\
\text { dan tampilan } \\
\text { active } \\
\text { berubah } \\
\text { dengan video } \\
\text { input dari } \\
\text { tampilan } \\
\end{array}$ & Berhasil \\
\hline
\end{tabular}

$\begin{array}{lll}\text { preview } & \text { dari } & \text { preview } \\ \text { dengan } & \text { tampilan } & \text { dengan } \\ \text { transisi } & \text { preview } & \text { transisi } \\ \text { fading sesuai } & \text { dan ada } & \text { fading sesuai } \\ \text { dengan } & \text { efek } & \text { dengan } \\ \text { gerakan } & \text { fading } & \text { gerakan } \\ \text { potensiometer } & \text { sesuai } & \text { potensiometer } \\ & \text { gerakan } & \\ & \text { switcher } & \end{array}$

Adapun untuk pengujian Audio pada Vmix ketika live stream Youtube dapat dilihat pada Tabel 2.

Tabel 2. Pengujian Audio potensiometer pada Vmix Console

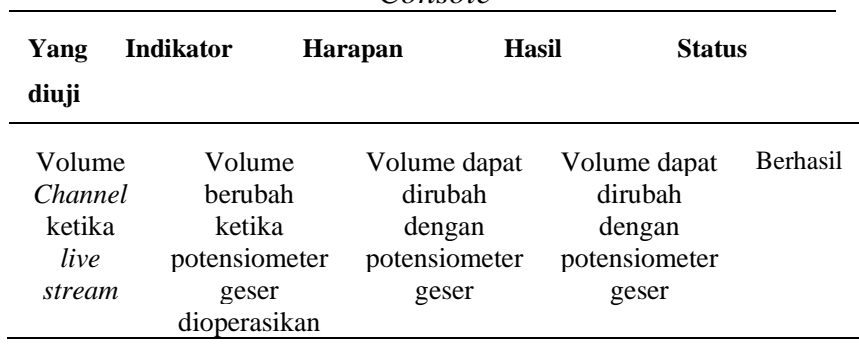

\subsection{Hasil Uji Coba Responden}

Pengujian juga dilakukan dengan hasil uji coba dengan responden. Responden yang aktif dalam proses editing audio dan video. dipilih untuk uji coba Audio Video Vmix Console diambil dari 5 mahasiswa Politeknik Elektronika Negeri Surabaya jurusan Teknologi Multimedia Broadcasting. Pengujian digunakan untuk mengetahui tingkat keberhasilan dari Audio Video Vmix Console yang dibuat. Pengujian akan dinilai dari sisi teknis dan sisi ergonomis. Daftar pertanyaan yang digunakan pada pengujian ini adalah sebagai berikut:

Sisi Teknis:

1. Seberapa baik alat ini ketika digunakan untuk mengendalikan switcher video pada software VMix?

2. Seberapa baik alat ini ketika digunakan untuk mengendalikan push button (active, preview, transition) pada software VMix?

3. Apakah potensiometer geser (switcher) cukup responsif ketika dioperasikan pada software VMix?

4. Apakah push button cukup responsif ketika dioperasikan pada software VMix? 
5. Bagaimana ketahanan dari potensiometer geser ketika sedang dioperasikan?

6. Bagaimana ketahanan dari push button ketika sedang dioperasikan?

Sisi Ergonomis:

1. Apakah pengurutan tombol pada alat ini mudah diingat?

2. Bagaimana jarak antar komponen yang ada pada alat ini?

3. Seberapa efektif alat ini untuk dibawa pada kegiatan mobile berdasarkan beratnya?

4. Seberapa efektif alat ini untuk dibawa pada kegiatan mobile berdasarkan ukurannya

5. Bagaimana pendapat anda tentang desain atau bentuk alat dari Audio Video Vmix Console?

6. Seberapa nyamankah ketika anda menggunakan alat ini untuk mengatur volume pada software VMix?

Setiap pertanyaan yang akan dijawab oleh responden memiliki pilihan jawaban berbentuk skala dengan nilai skor 1-4. Untuk hasil pengujian dengan responden dapat dilihat pada Tabel 3.

Tabel 3. Hasil pengujian dengan responden

\begin{tabular}{|l|l|l|l|l|l|l|l|l|l|l|l|l|}
\hline Sisi & \multicolumn{4}{|l}{ Teknis } & \multicolumn{4}{|l|}{ Ergonomis } \\
\hline \multirow{2}{*}{ Nama } & \multicolumn{4}{|l}{ Pertanyaan } & \multicolumn{4}{|l|}{ Pertanyaan } \\
\cline { 2 - 11 } & 1 & 2 & 3 & 4 & 5 & 6 & 1 & 2 & 3 & 4 & 5 & 6 \\
\hline M. Zafar Azizi & 4 & 4 & 4 & 4 & 4 & 4 & 4 & 4 & 4 & 4 & 4 & 4 \\
\hline Reza DwiFajar & 4 & 4 & 4 & 4 & 4 & 4 & 4 & 3 & 4 & 4 & 4 & 4 \\
\hline Hudzaifah R. & 4 & 4 & 4 & 4 & 3 & 4 & 4 & 3 & 4 & 4 & 4 & 3 \\
\hline Nina Kurniasari & 3 & 4 & 4 & 4 & 3 & 3 & 3 & 3 & 4 & 4 & 4 & 4 \\
\hline Nadhifah Amalia P.R. & 4 & 3 & 4 & 4 & 4 & 4 & 3 & 4 & 4 & 4 & 3 & 4 \\
\hline
\end{tabular}

Hasil perhitungan menggunakan Likert Scale. Rumus yang digunakan adalah sebagai berikut:

$$
\frac{\text { Jumlahhasilskoryangdidapatkan }}{\text { Jumlahtotalskor }} \times 100 \%
$$

Dengan rumus di atas maka didapatkan hasil sebagai berikut:

- Sisi teknis :

$$
\frac{115}{120} \times 100 \%=95 \%
$$

- Sisi Ergonomis:

$$
\frac{111}{120} \times 100 \%=92,5 \%
$$

Dengan pengujian dari sisi teknis dan sisi ergonomis memiliki hasil lebih dari $90 \%$.

\section{Kesimpulan}

Dari hasil penelitian yang telah dibuat, dapat diambil beberapa kesimpulan sebagai berikut:

1. Dengan adanya Audio Video Vmix Console ini, dapat menjadi alat alternatif yang dapat dipakai pada saat menggunakan software VMix untuk mempermudah saat akan melakukan mixing audio video.

2. Console yang dibuat memiliki bentuk desain dan ukuran yang mudah untuk dibawa pada saat kegiatan mobile.

\section{Saran}

Perlu adanya penelitian lebih lanjut terkait pemanfaatan Vmix Console sehingga mampu menunjang pemutaran Audio Video terlebih lagi jika kita terapkan pada era penyiaran jarak jauh seperti pada masa pandemi sekarang dimana penyesuaian hardware bisa lebih ditingkatkan lagi sehingga lebih ergonomis dan mendukung penyiaran jarak jauh.

\section{Daftar Pustaka}

[1] Woodroof,A \& Gormez, B. 2012, Laser Music System: Implemented using lasers, infrared sensors, photocells and a Arduino Microcontroller. Bachelor Thesis, School of Information Science, Computer and Electrical Engineering, Högskolan i Halmstad. Sweden.

[2] Pratama, A.N. 2015. Pengembangan MIDI Controller Berbasis Microcontroller Dengan Mekanisme Sentuh. Skripsi. FPBS, Pendidikan Seni Musik, Universitas Negeri Yogyakarta, Yogyakarta.

[3] Pernando, R.R., 2015, Rancang Bangun MIDI DJ Controller Berbasis Arduino. Tugas Akhir, DIII Teknik Telekomunikasi, Sekolah Tinggi Teknologi Telematika Telkom Purwokerto, Purwokerto. 
[4] Sugianto, 2007, Desain Rangkaian Elektronika dan Layout PCB dengan Protel 99 SE, PT. Elex Media Komputindo, Jakarta.

[5] Winarno, \& Arifianto, D., 2011, Bikin Robot Itu Gampang, PT. Kawan Pustaka, Jakarta Selatan.

[6] Nandayani, S., 2012, Kreasi Cantik Manik Akrilik, Kanaya Press, Jakarta.

[7] Haryanto, R., 2009, Cerdas Jelajah Internet, Kriya Pustaka, Jakarta.

[8] White, P., 2015, The SOS Guide to Live Sound: Optimizing Your Band's LivePerformance Audio, Focal Press, Burlington.

[9] Limbong, T., \& Simarmata, J., 2020, Media dan Multimedia Pembelajaran: Teori \& Praktik. Yayasan Kita Menulis.

[10] Mulyana, E., \& Kharisman, R., 2014, Perancangan Alat Peringatan Dini Bahaya Banjir dengan Mikrokontroler Arduino Uno R3, Citec Journal, Vol.1, No.3, 171-182.

[11] Wahyudi, U., 2018, Mahir dan Terampil Belajar Elektronika Untuk Pemula, CV. Budi Utama, Yogyakarta. 